\title{
Cardiovascular risk factors in sub-Saharan Africa: a review
}

\author{
Manuel Monti, ${ }^{1}$ Maria Pia Ruggieri, ${ }^{2}$ Giovanni Maria Vincentelli, ${ }^{3}$ Fernando Capuano, ${ }^{4}$ Francesco Rocco Pugliese ${ }^{5}$ \\ ${ }^{1}$ Emergency Department, AUSL Umbria1, Assisi (PG); ${ }^{2}$ Emergency Department, San Giovanni Hospital, Roma; ${ }^{3}$ Emergency \\ Department, Fatebenefratelli Hospital, Roma; ${ }^{4}$ Italian Association of Technical Health Workers of Biomedical Laboratory \\ (ANTeL), Roma; ${ }^{5}$ Emergency Department, Pertini Hospital, Roma, Italy
}

\begin{abstract}
Ischemic heart disease is increasing dramatically in the Sub-Saharan Africa (SSA), despite an increasing prevalence of risk factors, and some characteristics of the African people that make the African population subject to the effects of major cardiovascular risk factors. The pace and direction of economic development, rates of urbanization, the changes in life expectancy, associated with different pathophysiological factors are causing an increased rate of atherosclerotic disease in these countries. The prevalence of ischemic heart disease in SSA has shown a significant rise in the next two following decades due to the rising prevalence of risk factors, especially hypertension, diabetes, overweight and obesity, physical inactivity, tobacco use and the dyslipidemia, mainly due to an increase in urbanization. Moreover, thanks to new knowledge, it has been pointed out the difference of individual risk factors in the African population and other populations due to genetic differences. It is estimated that age-standardized approach for ischemic heart disease mortality rates will rise by $27 \%$ in African men and $25 \%$ in women by 2015 and by 70 and $74 \%$, respectively by 2030 . More research is needed in Africa to provide evidence for cardiovascular prevention and treatment to mitigate the oncoming epidemic. Health interventions are needed for preventing or reducing the morbidity/mortality and should be addressed to both children and adults, including score of the risk stratification modified, starting early and aggressive therapy, if necessary.
\end{abstract}

\section{Introduction}

Cardiovascular disease (CVD) is a disabling growing epidemic that causes premature death and decreased quality of life. Globally, CVDs, which include coronary heart disease (CHD), strokes, rheumatic heart disease, cardiomyopathy, and other heart diseases, represent the leading cause of death. ${ }^{1}$ Recent population studies demonstrate an increasing burden of CVD and related risk factors in sub-Saharan Africa (SSA). ${ }^{2}$ Despite evidence to suggest that CVD-related mortality rates are increasing in the region, it is only

Correspondence: Manuel Monti, USL UMBRIA1 U.O. $\mathrm{PS} / 118$, via V. Muller 1, Assisi (PG), Italy.

Tel.: +39.339.1050122.

E-mail: montimanuel@tiscali.it

Key words: Cardiovascular disease; cardiovascular risk factors; coronary heart disease; Sub-Saharan Africa.

Received for publication: 23 July 2014

Revision received: 3 September 2014.

Accepted for publication: 8 September 2014.

This work is licensed under a Creative Commons Attribution NonCommercial 3.0 License (CC BY-NC 3.0).

(C) Copyright M. Monti et al., 2015

Licensee PAGEPress, Italy

Italian Journal of Medicine 2015; 9:305-313

doi:10.4081/itjm.2015.533 now being recognized as an important public health issue in sub-Saharan Africa, with coronary artery disease shown to rise in incidence in sub-Saharan Africa. ${ }^{3,4}$ Cardiovascular diseases are the main noncommunicable conditions in SSA and now $9.2 \%$ of total deaths in the African region are caused by $\mathrm{CVD},{ }^{5}$ being the leading cause of death in the population aged over $45 .{ }^{6}$ Cardiovascular diseases account for $7-10 \%$ of all adult medical admissions to hospitals in Africa, with heart failure contributing to $3-7 \% .{ }^{7}$ When studies on urban and rural populations were analyzed, the prevalence of CVD was found to be higher in the urban than the rural population. ${ }^{8,9}$

\section{Behavioral risk factors}

The important contributors to this transition are the so-called globalization of dietary habits and urbanization. Urbanization is the prime driver for nutrition transition and emergence of obesity, the metabolic syndrome and other non-communicable diseases in developing countries, especially SSA. The current average annual growth of the urban population in subSaharan Africa is 4.5\%. Over the period 1980-2050, the urban population of Africa, as a whole, is expected to increase from 134 million to $1,264,000$ million. ${ }^{10}$ The rural-to-urban migration in many of the developing countries exposes migrants to urbanized diets and lifestyle. Dietary changes associated with urbanization are related to the fact that rural dwellers tend to be more self-reliant in obtaining food and also tend to eat 
traditional diets that are high in grains, fruit and vegetables, and low in fat. Once they arrive in urban areas, these same people tend to rely more on external forces for sustenance, resulting in a shift from production of their own food to the purchase of processed foods. ${ }^{11}$ Major dietary changes include a large increase in the consumption of fats, particularly animal fat and added sugar and a decrease in cereal and roughage intake. ${ }^{12}$ This involves major changes of the main cardiovascular risk factors between the two areas ${ }^{13}$ (Table 1). There was evidence of a significant increase in edible oil, indicating a major change in diet; dietary changes include a large increase in the consumption of fats, particularly animal fat and added sugar, associated with the decrease in cereal and fiber intake ${ }^{14}$ (Figure 1). In fact, recent global figures from the World Health Organization (WHO) indicate that the prevalence of obesity is not just affecting the developed countries, but is also increasing in the developing countries, where over 115 million people suffer from obesity-related problems. ${ }^{15}$

\section{Psychosocial factors}

Psychosocial factors increase the number of risk factors. Some studies have shown that the number of countries registering, in recent years, a rise in the number of households owning televisions and computers is inversely proportionate to the reduction in physical activities, contributing to the obesity rise in children. ${ }^{16,17}$ Alcohol and tobacco smoking are risk factors towards heart failure, ischemic stroke, heart disease, and acute myocardial infarction. ${ }^{18}$ Many studies show how alcohol and tobacco use is related to poverty and low socio-economic positions. Rural areas inhabitants are highly affected by such habits, especially compared to the other risk factors, which are more common in urban areas. ${ }^{19,20}$ Smoking tendency is increasing among men and women in SSA, mainly in the age group between 30 and 49, with particular reference to women, increasing together with ageing. ${ }^{21}$ Furthermore, in many developing countries, psychosocial attitude towards obesity is not seen as a negative factor. ${ }^{22,23}$ Mvo et al. and Puoane et al. reported

Table 1. The main risk factors of urban and rural area.

\begin{tabular}{lcc}
\hline & Urban & Rural \\
\hline BMI $\left(\mathrm{kg} / \mathrm{m}^{2}\right)$ & $25.8 \pm 6.9$ & $19.3 \pm 3.2^{*}$ \\
\hline Waist $(\mathrm{cm})$ & $85.2 \pm 9.9$ & $67.8 \pm 9.9^{*}$ \\
\hline Waist-hip ratio & $0.88 \pm 0.09$ & $0.81 \pm 0.08^{*}$ \\
\hline Triceps skinfold $(\mathrm{mm})$ & $17.3 \pm 6.8$ & $9.8 \pm 5.4^{*}$ \\
\hline$\%$ overweight $(\mathrm{BMI}>25)$ & 53.4 & $5.8^{*}$ \\
\hline
\end{tabular}

BMI, body mass index. ${ }^{*}<<0.001$, age and gender adjusted. that even if a large percentage of African women were overweight and obese, only a few perceived themselves so. ${ }^{24,25}$ Gambian populations were reported to be more obesity tolerant (acceptance of obese body size as normal) than African-Americans, and much more tolerant than white Americans. ${ }^{26}$ Moreover, the double burden of under and over-nutrition presents a potentially grave situation, which should deserve more attention from both health and economic agencies engaged in development. While they continue to deal with the problems of infectious disease and under-nutrition, they are experiencing a rapid upsurge in disease risk factors, such as obesity and overweight, especially in urban settings. It is not uncommon to find under-nutrition and obesity existing side-by-side within the same country, the same community and the same household. Children in low and middle-income countries are more vulnerable to inadequate pre-natal, infant and young child nutrition. Simultaneously, they are exposed to high-fat, high-sugar, high-salt, energydense, micronutrient-poor foods, which are usually lower in cost but also lower in nutrient quality. These dietary patterns, in conjunction with lower levels of physical activity, result in sharp increases in childhood obesity, while undernutrition issues remain unsolved. ${ }^{27}$ Recently, the rise of obesity and cardiovascular risk factors were also seen in rural areas of some countries of the developing world. It has to be pointed out that many so-called rural areas are no longer genuinely rural: people are becoming more urbanized even in those areas far from cities. This phenomenon, to some extent, is linked to the so-called Remittance economy. Migrant workers remittance led to a relative wealth, even in rural areas influencing some lifestyles. ${ }^{28}$ Such epidemiological transition is due, in part, to an improved longevity starting from the 1950 s, so that more people are exposed to these risk factors, for long enough periods, to cause coronary artery disease (CAD). Globally considering risk factors, it has to be highlighted how the risk-factor burden experienced by blacks differs from that of whites. A recent study conducted in Ghana shows low median levels of cardiovascular risk factors and the prevalence of obesity, hypertension, dysglycemia or diabetes, and dyslipidemia was low too. The preponderance of moderately elevated levels of C-reactive protein was also low. However, the evidence has shown that younger patients $(<55$ years $)$ were prone to a higher risk of atherosclerotic disease, which decreased ageing. ${ }^{29}$ Such difference, could be partially explained by the difficult collection of data about the actual incidence of risk factors among African population, which may lie in the complexity of conducting proper surveys in many countries, in order to perform an accurate risk stratification. In addition, women do not smoke or drink publicly, but it can assume that the women exhibit these 
behaviors privately in smaller proportions.$^{30}$ Moreover there are some pathophysiological peculiarities in the African population, boosting an increased susceptibility to traditional cardiovascular risk factors.

\section{Arterial hypertension}

The prevalence of hypertension among urban dwellers in SSA appears to be particularly high, ranging from 8-25 per cent. At the dawn of the twentieth century, high blood pressure was virtually nonexistent among indigenous Kenyans and Ugandans. Starting from 1975, high blood pressure became established in Cameroon, Côte d'Ivoire, Democratic Republic of Congo, Ghana, Kenya, Nigeria, and Uganda. ${ }^{31,32}$ In December 2006, among the adults living in Addis Abeba, the prevalence of hypertension was $50.9 \%$ among males and $47.1 \%$ among females. ${ }^{33}$ In Cameroon the prevalence of hypertension among people aged 15-99 in 2004 was $20.8 \%$, a common issue especially among men. ${ }^{34}$ In Sub-Saharan Africa, ageadjusted hypertension prevalence and age-specific rates of death from stroke are higher among urban blacks than equivalent white populations. ${ }^{35}$ Yameogo et al. showed resistant hypertension is common in black Africans, and the most affected subjects are people over 60, with limited economic income and living in rural areas. ${ }^{36}$ Numerous studies have found that such population has an excess prevalence of salt sensitivity, hypervolemia, and low plasma renin activity. ${ }^{37,38}$

\section{Diabetes mellitus}

In 2010, an estimated 12.1 million people with diabetes mellitus ( $4.2 \%$ of the global estimate of 285 million) were living in sub-Saharan Africa. ${ }^{39}$ The following year, diabetes prevalence rose to 14.7 million $(4.02 \%$ of the global 366 million). By year 2030, a 90\% projected increase in diabetes prevalence throughout SSA, will skyrocket the number of Africans with diabetes to 28 million. ${ }^{39}$ The incidence of diabetes mellitus in inherited heart diseases (IHD) remains uncertain because many studies show that, among African population, the main complication of diabetes is the micro-angiopathies compared to Western countries, where the macrovascular complication is the most important. ${ }^{40,41}$ One common pathogenic mechanism for microvascular disease, is rooted in the chemical by-products of reactions between sugars and proteins occurring over the course of days to weeks, producing irreversible protein cross-linked derivatives advanced glycation end (AGE)-product. ${ }^{42}$ The increase in AGE produces growth inhibition and apoptosis of retinal pericytes, also inducing an overproduction of endothelial growth factors, neovascularization, and chronic inflammation. ${ }^{43,44}$ Such actions lead to an increased microthrombosis, capillary blockage, retinal ischemia and the activation of endothelial cells, responsible for important shortcomings involving mesangial cells and stimulating glomerular fibrosis. . $^{45,46}$ It has been suggested that, among black population, microvascular damage is due to a different genetic predisposition that stimulates the accumulation of AGEs with all the after-effects. ${ }^{45,46}$ The strong association between diabetes mellitus and hypertension among the African population, compared to the white population, worsens dramatically microvascular damage. ${ }^{47,48}$

\section{Visceral fat}

The phenotype of obesity, found among several ethnic groups in developing countries, appears to be different than among the Caucasian population. Sev-

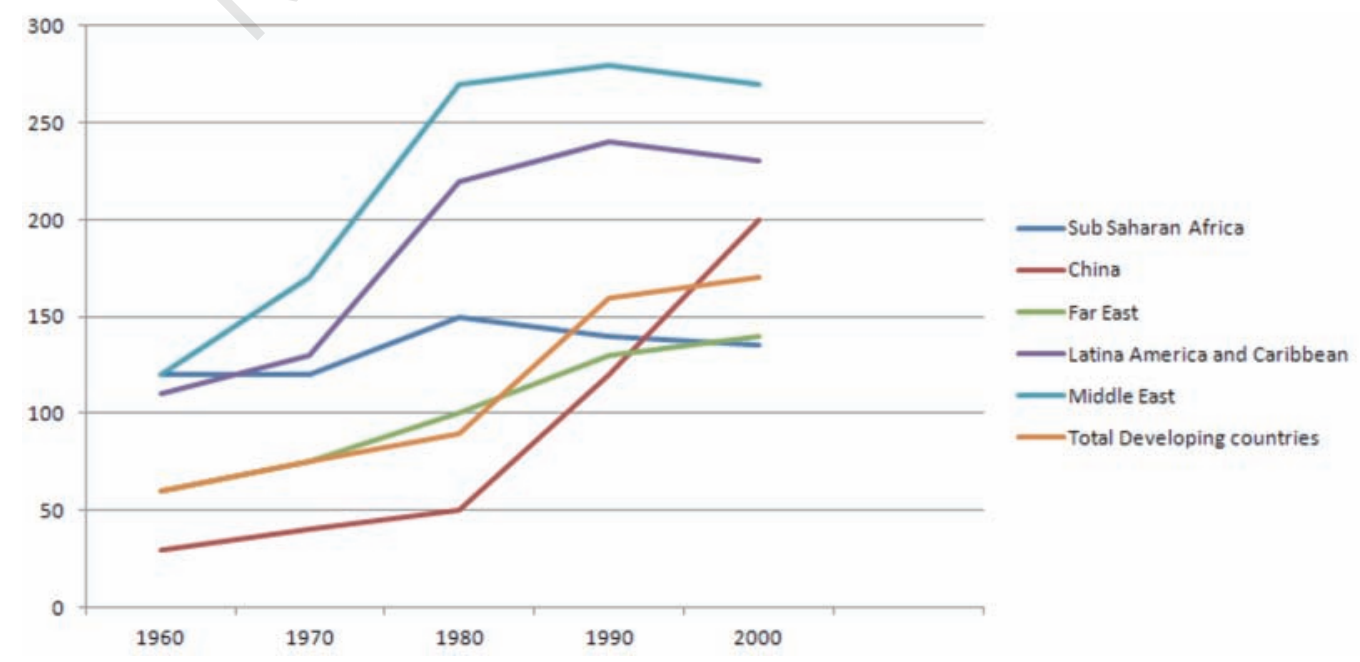

Figure 1. Date of consumption of fats (data from Institute of Medicine, 2010 $0^{14}$ ). 
eral studies reported a correlation between visceral fat (VF) and insulin-resistance, rise of triglycerides, blood pressure and metabolic syndrome. Moreover, VF is correlated to all the conventional cardiovascular disease risk factors and with sedentary life-styles. VF might exhibit a proinflammatory adipokine profile, playing a pivotal role in coronary atherogenesis. The expansion of adipocytes with triglyceride is thought to trigger the increased expression and production of inflammatory cytokines - such as tumor necrosis factor- $\alpha$, monocyte chemoattractant protein- 1 , IL- $1 \beta,-6$, and -8 , plasminogen activator inhibitor- 1 and decreased expression and production of leptin and vasoprotective adiponectin. Furthermore, VF might exhibit a proinflammatory adipokine profile $e^{49,50}$ (Figure 2). During the International Day for evaluation of abdominal obesity, a study, related to the waist circumference data, involving 63 countries, showed highest prevalence of visceral fat in SSA and South Asians, compared with North Europeans and other Asian ethnic groups. ${ }^{51}$ In fact, it was shown that a parity of average value of waist circumference and body mass index (BMI) in SSA, especially Nigeria and Cameroon, visceral adiposity is significantly higher than in other populations. ${ }^{52}$ High percentage of body fat with low BMI value could be partly explained by body build (trunk to leg length ratio and slender body frame), muscularity, adaptation to chronic calorie deprivation, and ethnicity. ${ }^{53}$ Some studies have also shown how the populations of SSA have an accumulation of visceral fat in other tissues where usually are not deposited (ectopic fat): this feature has the potential to affect insulin sensitivity. ${ }^{54} \mathrm{~A}$ number of studies highlighted how African populations have a lower amount of epicardial fat than the white population: such matter is of considerable interest, as the epicardial fat is now considered as an important emerging independent cardiovascular risk factor ${ }^{55}$ (Figure 3). The markers of body fat distribution, including waist-hip ratio, abdominal subcutaneous and visceral fat diner a heritable component, support the thesis of unique genetic variants associated with ectopic fat depots. ${ }^{56-58}$ Fox et $a l$. identified a single nucleotide polymorphisms near the TRIB2 locus, which is associated with pericardial fat but not with body mass index or visceral abdominal fat. ${ }^{59}$ This is the reason why we must carry out studies in order to highlight, among the African population, the genetic variants responsible for the increase in visceral fat but not in epicardial ectopic. This would allow the identification of subgroups among the population, with BMI and amount of visceral fat complying with the standard, who are at greater risk of atherosclerotic disease. ${ }^{60}$ Other factors, such as genotype, could make the African population very susceptible to visceral fat. Among others genetics, a pivotal role is fulfilled by lectin-like oxidized low-density

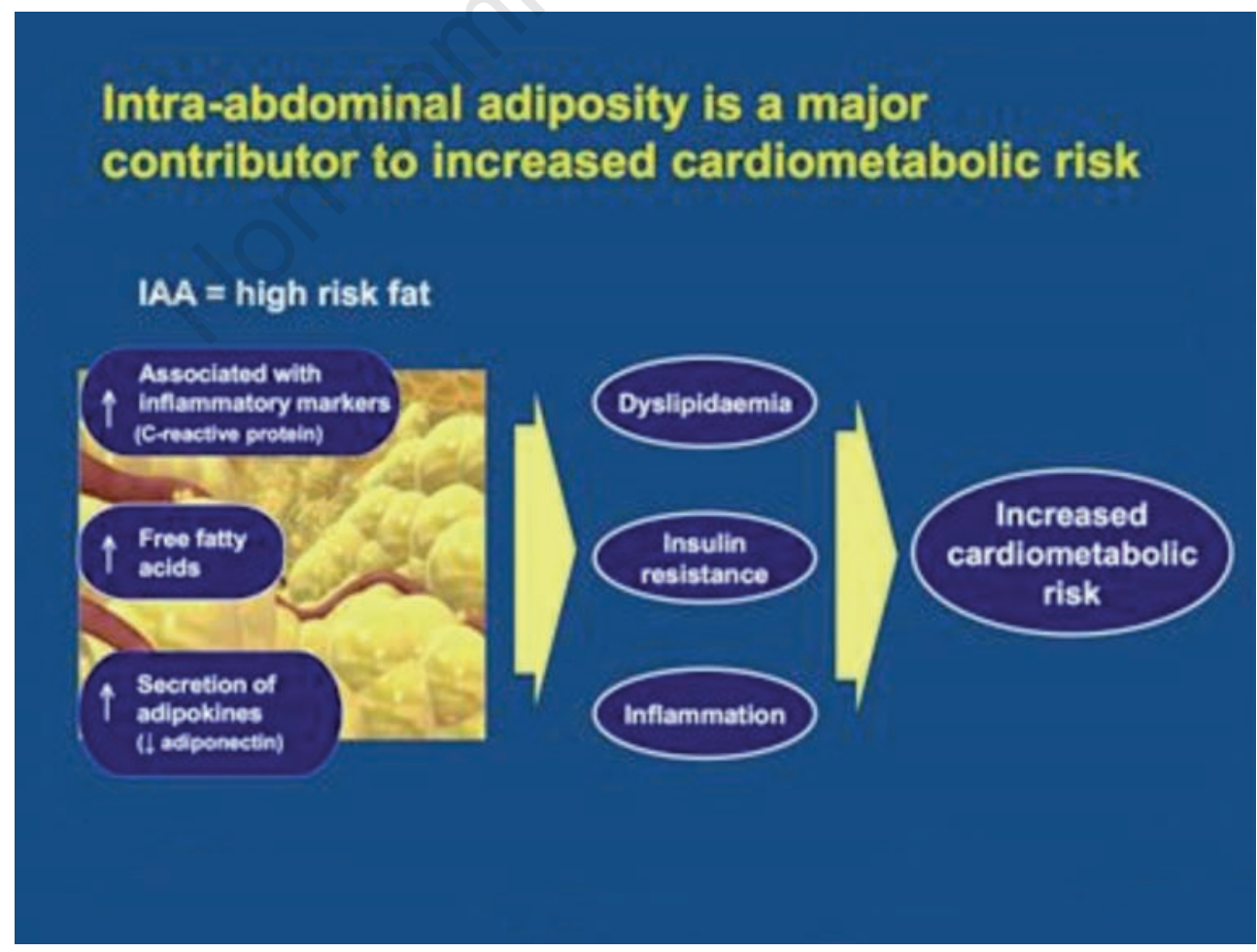

Figure 2. Main mechanisms of cardiovascular damage caused by visceral fat. IAA, intra-abdominal adiposity. 
lipoprotein receptor-1 (LOX-1), a type-II membrane protein belonging to the C-type lectin family. The LOX-1 plays a crucial part in amplifying local inflammatory responses during atherosclerotic development $^{61}$ (Table 2). The study performed by Predazzi showed a higher frequency of two polymorphisms associated with the risk for CAD and acute myocardial infarction, among the South-Saharan rural populations. ${ }^{61}$ Furthermore, it must be considered the identification of other deleterious alleles lying on CVD-associated genes (GJA4, SERPINE1 and $M M P 3)$, which have a higher frequency in African population compared to Europeans. ${ }^{62}$

\section{Communicable diseases}

Several studies reported associations between the exposure to various infectious agents and the prevalent coronary disease. ${ }^{63-65}$ In 1891, Huchard was the first to suggest the involvement of infectious agents in the process of atherosclerosis. Subsequently, several reports shown a relationship between the development of atherosclerosis and the presence of infectious diseases. ${ }^{66,67}$ Several types of microbes are now also being implicated as possible causative agents in acquired CVD, and few bacterial agents have been a research topic for several years. Organisms such as the spirochetes Borrelia burgdorferi (Lyme disease) or the Treponema pallidum (syphilis), and flagellated bacteria such as the streptococci, have well-recognized atherosclerotic potential. Interest in the role of infection in atherosclerosis was renewed with the observation that patients with coronary artery disease were more likely than matched controls to have an elevated antibody titer to Chlamydia pneumonia. ${ }^{68,69}$ Multiple com- plex processes are involved in the development of CVD. The increased incidence of infectious diseases has highlighted the expression of proinflammatory immune system to survive up to older ages. Although the increase in the protein $\mathrm{c}$ was not related to an increase in atherosclerotic disease, other acute-phase reactants, including fibrinogen and serum amyloid A, appeared to be associated with vascular risk. This selection of a proinflammatory status is confirmed by the higher levels of the proinflammatory cytokine, including the interleukin- $6{ }^{70}$ The macrophage is a critical component

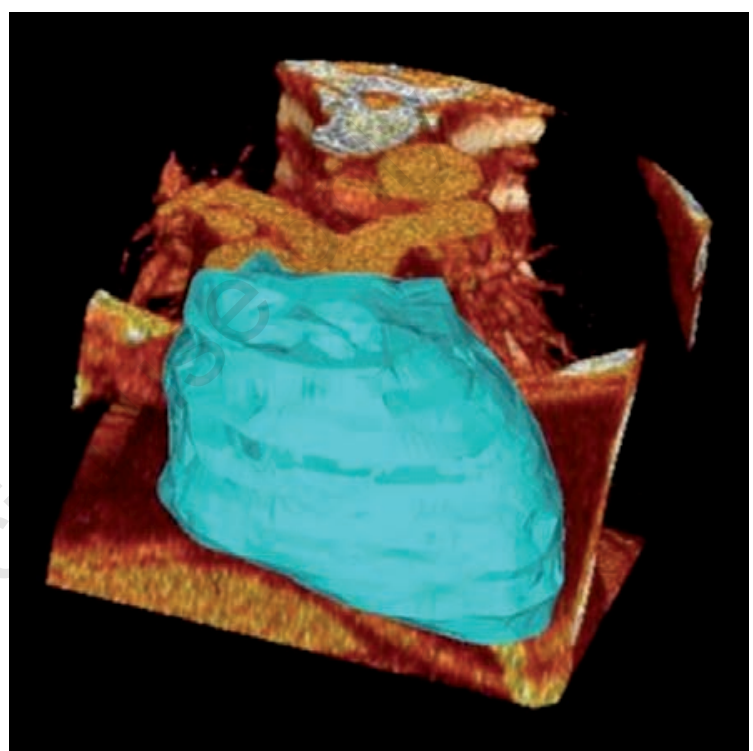

Figure 3. Epicardial fat around the myocardial tissue.

Table 2. Cellular effects of ligand-lectin-like oxidized low-density lipoprotein receptor-1 interaction on atherogenesis.

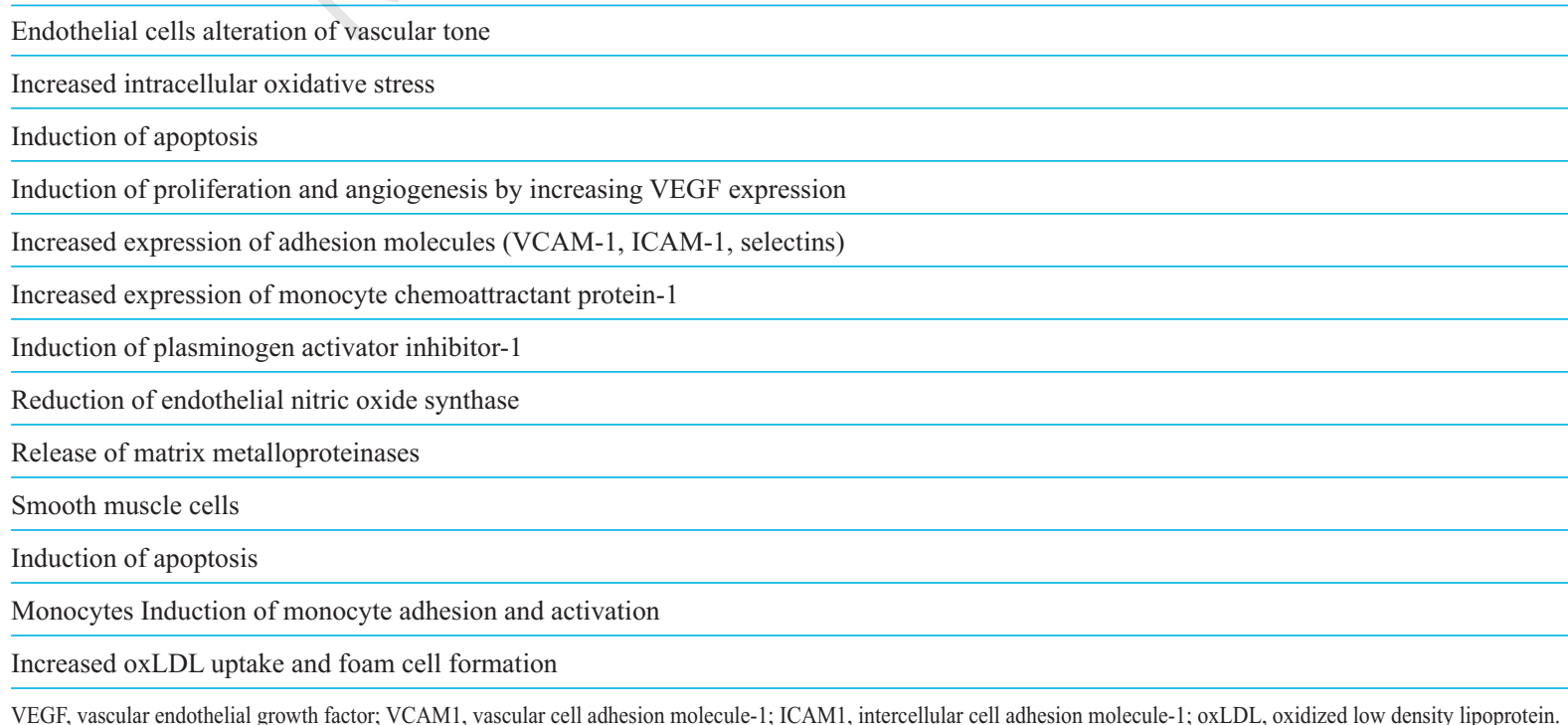


in the pathway to atherosclerotic inflammation. During an infectious process causes the activation of macrophages, including the secretion of numerous factors (angiopoietin-related growth factor; transforming growth factor; fibroblast growth factor-1, $-2,-4$; vascular endothelial growth factor). These substances stimulate the appearance of endothelial cells and are responsible for the creation of a systemic hypercoagulable state. ${ }^{71,72}$ In addition, mitogenic factors are released through an NF- $\kappa \beta$ related mechanism, leading to smooth muscle cell proliferation and however there is an increase of monocytes through transendothelial migration at coronary level. ${ }^{73,74}$ This means that the activated macrophages stimulate both local lipid accumulation and the instability that presages plaque rupture..$^{75-77}$

\section{Coronary heart disease}

IHD remains relatively uncommon in SSA despite an increasing prevalence of risk factors but its incidence is rising. A study of the 1954 have been evidenced by 3500 postmortem studies in Ghana in which only three cases of CHD were found. ${ }^{78}$ In Uganda, the National Heart Institute at Mulago alone, currently receives at least 100 patients every day with 5-8 being new cases (a total of about 36,500 patients per year with 1825-2920 being new cases). In 2011, heart cases increased by $20 \%$ bringing the number to 12,000 with 256 new cases registered in January alone..$^{79}$ The WHO estimated that in 2005, IHD caused approximately 261,000 deaths in the African region, and current projections suggest that this number will be nearly 600,000 by 2030 . It is estimated that agestandardized mortality rates for IHD will rise by $27 \%$ in African men and 25\% in women by 2015, and by 70 and $74 \%$, respectively by $2030^{80}$ (Figure 4 ). The increase in IHD in Sub-Saharan Africa since the 1980s is presumably due to the increasing prevalence among African populations of the classical risk factors for $\mathrm{CAD}$, including hypertension, smoking, diabetes, abdominal obesity and dyslipidemia. In addition, as a re-

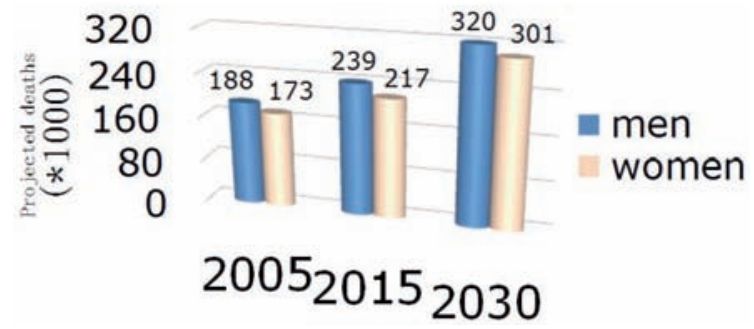

Figure 4. Projection of death from inherited heart diseases in men and women in the WHO African regions for the year 2005, 2015 and 2030 (data from Onen, 2013 ${ }^{81}$ ). sult of developments in combating communicable diseases and a decrease in childhood mortality, life expectancy in Sub-Saharan Africa has risen since the 1950 s and the number of individuals aged over 60 is predicted to increase from 39 to 80 million by 2025 in SSA. This means that more people are exposed to these risk factors for long enough periods to cause CAD. ${ }^{81-83}$

\section{Conclusions}

This review attempts to assess the prevalence, levels of risk and major risk factors for developing for cardiovascular disease in SSA. This article answered specific research questions and hypotheses on issues related to sedentary lifestyles, nutritional behaviors, knowledge on CVDs risk factors, and especially some of the key knowledge on the genetic differences between the African population and other populations. Among the socio-economic and behavioral risk profile study variables, the review documented a high prevalence of active smoking, high consumption of edible oil and fat, an increase in physical inactivity and current active alcohol usage. The economic and social important consequences of the CVD Epidemics in the SSA will be devastating. Important gene - environment can play a crucial role in the increased risk of the IHD of the African population. The detection and management of hypertension and diabetes are still unsatisfactory in inner city areas and show variations by ethnic origin. A priority should be the development of scores for the population of Africa, also using the emerging risk factors such as calcium score and visceral fat and considering genetic differences. Increasing burden of obesity, the metabolic syndrome, diabetes mellitus type 2, and CVD in SSA has created an urgent need to strategize mass health policies and intervention programs to tackle nutrition and continuing efforts to manage undernutrition. There are two major approaches to prevention: public health/community-based and clinic-based strategies with a targeted approach to high-risk patients and combinations of these. There are concerns that in comparison with communicable diseases, cardiovascular and relatively chronic diseases have a low priority in the global health agenda and that require this additional emphasis. Finally, we must consider, in the light of the differences between races, strategies for the control of CHD and stroke cushion adopted in European countries directed mostly to white rural populations may be inappropriate for the African population. In conclusion, evaluations must be performed carefully for correct risk stratification, the timing of initiation of treatment and the goals of the therapeutic treatment to be achieved in the African population. In addition, further evaluations should be made to perform correct 
public health/community-based strategies targeted at risk factors, including decrease in taxes and prices of fruits and vegetables, more playgrounds, parks, walking and bicycle tracks, provide information to parents about nutrition (particularly mothers), the change of food policy through country-specific guidelines for a healthy nutrition of adults and children.

\section{References}

1. Roger VL, Go AS, Lloyd-Jones DM, et al. Heart disease and stroke statistics--2011 update: a report from the American Heart Association. Circulation 2011;123:e18e209.

2. Hertz JT, Reardon JM, Rodrigues CG, et al. Acute myocardial infarction in sub-saharan Africa: the need for data. PLoS One 2014;9:e96688.

3. Opie LH. Heart disease in Africa. Lancet 2006;368: 449-50.

4. Ntsekhe M, Damasceno A. Recent advances in the epidemiology, outcome, and prevention of myocardial infarction and stroke in sub-Saharan Africa. Heart 2013;99: 1230-5.

5. Sampson UK, Amuyunzu-Nyamongo M, Mensah GA. Health promotion and cardiovascular disease prevention in sub-Saharan Africa. Prog Cardiovasc Dis 2013;56: 344-55.

6. Gaziano TA. Economic burden and the cost-effectiveness of treatment of cardiovascular diseases in Africa. Heart 2008;94:140-4.

7. Mocumbi AO. Lack of focus on cardiovascular disease in sub-Saharan Africa. Cardiovasc Diagn Ther 2012; 2:74-7.

8. Amoah AGB. Sociodemographic variations in obesity among Ghanaian adults. Public Health Nutr 2003;6:751-7.

9. Agyemang C, Owusu-Dabo E, de Jonge A, et al. Overweight and obesity among Ghanaian residents in The Netherlands: how do they weigh against their urban and rural counterparts in Ghana? Public Health Nutr 2009; 12:909-16.

10. Population Division, Department of Economic and Social Affairs, United Nations Secretariat. World urbanization prospects - the 2011 revision - data tables and highlights. ESA/P/WP.173; 20 March 2002, pp 66. Available from: http://www.un.org/esa/population/publications/wup2001/wup2001dh.pdf

11. Drewnowski A, Popkin BM. The nutrition transition: new trends in the global diet. Nutr Rev 1997;55:31-43

12. Misra A, Singhal N, Khurana. Obesity, the metabolic syndrome, and type 2 diabetes in developing countries: role of dietary fats and oils. L J Am Coll Nutr 2010; 29: 289S-301S.

13. Teo K, Chow CK, Vaz M, et al. The Prospective Urban Rural Epidemiology (PURE) study: examining the impact of societal influences on chronic noncommunicable diseases in low-, middle-, and high-income countries. Am Heart J 2009;158:1-7.

14. Institute of Medicine. Promoting cardiovascular health in the developing world: a critical challenge to achieve global health. Washington, DC: The National Academies Press; 2010.

15. Cappuccio FP, Kerry SM, Adeyemo A, et al. Body size and blood pressure: an analysis of Africans and the African diaspora. Epidemiology 2008;19:38-46.

16. Sturm R. Childhood obesity-what we can learn from existing data on societal trends, part 1. Prev Chronic Dis 2005;2:A12.

17. Milton K, Macniven R, Bauman A. Review of the epidemiological evidence for physical activity and health from low- and middle-income countries. Glob Public Health 2014;9:369-81.

18. Ormel J, Von Korff M, Burger H, et al. Mental disorders among persons with heart disease-results from World Mental Health surveys. Gen Hosp Psychiatry 2007;29: 325-34.

19. Schneider M, Bradshaw D, Steyn K, et al. Poverty and non-communicable diseases in South Africa. Scand J Public Health 2009;37:176-86.

20. Christensen DL, Friss H, Mwaniki DL, et al. Prevalence of glucose intolerance and associated risk factors in rural and urban populations of different ethnic groups in Kenya. Diabetes Res Clin Pract 2009;84:303-10.

21. Townsend L, Flisher AJ, Gilreath T, King G. A systematic literature review of tobacco use among adults 15 years and older in sub-Saharan Africa. Drug Alcohol Depend 2006;84:14-27.

22. Litllewood R. Commentary: globalization, culture, body image, and eating disorders. Cult Med Psychiatry 2004; 28:597-602.

23. Flynn KJ, Fitzgibbon M. Body images and obesity risk among black females: a review of the literature. Ann Behav Med 1998; 20:13-24

24. Mvo Z, Dick J, Steyn K. Perceptions of overweight African women about acceptable body size of women and children. Curationis 1999;22:27-31.

25. Puoane T, Fourie JM, Shapiro M, et al. "Big is beautiful" - an exploration of urban black women in South Africa. S Afr J Clin Nutr 2005;18:6-15.

26. Siervo M, Grey P, Nyan OA, Prentice AM. A pilot study on body image, attractiveness and body size in Gambians living in an urban community. Eat Weight Disord 2006;11:100-9.

27. Vorster HH, Kruger A, Margetts BM. The nutrition transition in Africa: can it be steered into a more positive direction? Nutrients 2011;3:429-41.

28. Prentice AM. The emerging epidemic of obesity in developing countries. Int J Epidemiol 2006;35:93-9.

29. Koopman JJ, van Bodegom D, Jukema JW, Westendorp RG. Risk of cardiovascular disease in a traditional African population with a high infectious load: a population-based study. PLoS One 2012;7:e46855.

30. Mensah G. Ischaemic heart disease in Africa. Heart 2008;94:836-43.

31. Jamison DT, Feachem RG, Makgoba MW, et al. Disease and mortality in Sub-Saharan Africa. 2nd ed. Washington (DC): World Bank; 2006.

32. Wamala JF, Karyabakobo Z, Ndungutse D, Guwatudde D. Prevalence factors associated with hypertension in Rukungiri district, Uganda - a community based study. Afr Health Sci 2009;9:153-60.

33. Tesfaye F, Byass P, Wall S, et al. Association of smoking and khat (Catha edulis Forsk) use with high blood pressure among adults in Addis Ababa, Ethiopia, 2006. Prev Chronic Dis 2008;5:A89.

34. Wamala JF, Karyabakobo Z, Ndungutse D, Guwatudde 
D. Prevalence factors associated with hypertension in Rukungiri district, Uganda - a community based study. Afr Health Sci 2009;9:153-60.

35. Opie L, Steyn K. Rationale for the hypertension guidelines for primary care in South Africa. South Afr Med J 1995;85:1325-28.

36. Yaméogo NV, Samadoulougou AK, Kagambèga LJ, et al. Epidemiological characteristics and clinical features of black African subject's resistant hypertension Ann Cardiol Angeiol (Paris) 2014;63:83-8.

37. Jamerson KA. Rationale for angiotensin II receptor blockers in patients with low-renin hypertension. Am J Kidney Dis 2000;36:S24-30.

38. Ferdinand KC, Armani AM. The management of hypertension in African Americans. Crit Pathw Cardiol 2007;6:67-71.

39. International Diabetes Federation. IDF diabetes atlas. 4th ed. International Diabetes Federation; 2009. Available from: https://www.idf.org/sites/default/files/IDFDiabetes-Atlas-4th-edition.pdf

40. Onen CL. Diabetes and macrovascular complications in adults in Botswana. MD thesis. Kampala: Makerere University; 2010.

41. Mbanya JC, Sobngwi E. Diabetes microvascular and macrovascular disease in Africa. J Cardiovasc Risk 2003;10:97-102.

42. Brownlee M, Cerami A, Vlassara H. Advanced glycosylation end products in tissue and the biochemical basis of diabetic complications. N Engl J Med 1988;318: 1315-21.

43. Yamagishi S, Hsu CC, Taniguchi M, et al. eceptor-mediated toxicity to pericytes of advanced glycosylation end products: a possible mechanism of pericyte loss in diabetic microangiopathy. Biochem Biophys Res Commun 1995;213:681-7.

44. Stitt AW, Jenkins AJ, Cooper ME. Advanced glycation end products and diabetic complications. Expert Opin Investig Drugs 2002;11:1205-23.

45. Yamagishi S, Amano S, Inagaki Y, et al. Advanced glycation end products-induced apoptosis and overexpression of vascular endothelial growth factor in bovine retinal pericytes. Biochem Biophys Res Commun 2002; 290:973-8.

46. Matsumura T, Yamagishi S, Brownlee M. Advanced glycation end products and the pathogenesis of diabetic complications. In: LeRoith D, Taylor S, Olefsky JM, eds. Diabetes mellitus: a fundamental and clinical text. Philadelphia, PA: Lippincott Williams \& Wilkins; 2000. pp 983-991.

47. Mbanya JC, Sobngwi E. Diabetes in Africa. Diabetes microvascular and macrovascular disease in Africa. J Cardiovasc Risk 2003;10:97-102.

48. Mohan V, Seedat YK, Pradeepa R. The rising burden of diabetes and hypertension in southeast asian and african regions: need for effective strategies for prevention and control in primary health care settings. Int J Hypertens 2013;2013:409083.

49. Sacks HS, Fain JN. Human epicardial adipose tissue: a review. Am Heart J 2007;153:907-17.

50. Mahabadi AA, Massaro JM, Rosito GA, et al. Association of pericardial fat, intrathoracic fat, and visceral abdominal fat with cardiovascular disease burden: the Framingham Heart Study. Eur Heart J 2009;30:850-6.
51. Balkau B, Deanfield JE, Despres JP, et al. International day for the evaluation of abdominal obesity (IDEA): a study of waist circumference, cardiovascular disease, and diabetes mellitus in 168,000 primary care patients in 63 countries. Circulation 2007;116:1942-51.

52. Okosun IS, Rotimi CN, Forrester TE, et al. Predictive value of abdominal obesity cut-off points for hypertension in blacks from West African and Caribbean island nations. Int J Obes Relat Metab Disord 2000;24:180-6.

53. Misra A, Wasir JS, Vikram NK. Waist circumference criteria for the diagnosis of abdominal obesity are not applicable uniformly to all populations and ethnic groups. Nutrition 2005;21:969-76.

54. Garg A, Misra A. Hepatic steatosis, insulin resistance, and adipose tissue disorders. J Clin Endocrinol Metab 2002;87:3019-22.

55. Willens HJ, Gómez-Marín O, Chirinos JA, et al. Comparison of epicardial and pericardial fat thickness assessed by echocardiography in African American and non-Hispanic White men: a pilot study. Ethn Dis 2008; 18:311-6

56. Fox CS, Massaro JM, Hoffmann U, et al. Abdominal visceral and subcutaneous adipose tissue compartments: association with metabolic risk factors in the Framingham Heart Study. Circulation 2007;116:39-48 .

57. Sellers TA, Drinkard C, Rich SS, et al. Familial aggregation and heritability of waist- to- hip ratio in adult women: the Iowa Women's Health Study. Int J Obes Relat Metab Disord 1994;18:607-13.

58. Kilpeläinen TO, Zillikens MC, Stancakova A, et al. Genetic variation near IRS1 associates with reduced adiposity and an impaired metabolic profile. Nat Genet 2011;43:753-60.

59. Fox CS, White CC, Lohman K, et al. Genome-wide association of pericardial fat identifies a unique locus for ectopic fat. PLoS Genet 2012;8:e1002705.

60. Willens HJ, Gómez-Marín O, Chirinos JA, et al. Comparison of epicardial and pericardial fat thickness assessed by echocardiography in African American and non-Hispanic White men: a pilot study. Ethn Dis 2008; 18:311-6.

61. Predazzi IM, Martínez-Labarga C, Vecchione L, et al. Population differences in allele frequencies at the OLR1 locus may suggest geographic disparities in cardiovascular risk events. Ann Hum Biol 2010;37:136-48.

62. Lanfear DE, Marsh S, Cresci S, et al. Genotypes associated with myocardial infarction risk are more common in African Americans than in European Americans. J Am Coll Cardiol 2004;7;44:165-7.

63. Saikku P, Mattila K, Nieminen MS, et al. Serological evidence of an association of a novel Chlamydia, TWAR, with chronic coronary heart disease and acute myocardial infarction. Lancet 1988;2:983-6.

64. Thom DH, Grayston JT, Siscovick D, et al. Association of prior infection with Chlamydia pneumoniae and angiographically demonstrated coronary artery disease. JAMA 1992;268:68-72.

65. Mendall MA, Carrington D, Strachan DP, et al. Chlamydia pneumoniae: risk factors for seropositivity and association with coronary heart disease. J Infect 1995;30: 121-8.

66. Benditt EP, Barrett T, McDougall JK. Viruses in the etiology of atherosclerosis. Proc Natl Acad Sci U S A 1983;80:6386-9. 
67. Grayston JT, Kuo CC, Campbell LA, Benditt EP. Chlamydia pneumoniae, strain TWAR and atherosclerosis. Eur Heart J 1993;14:66-71.

68. Dunne M. The evolving relationship between Chlamydia pneumoniae and atherosclerosis. Curr Opin Infect Dis 2000;13:583-91.

69. Berger M, Schroder B, Daeschlin G, et al. Chlamydia pneumoniae DNA in non-coronary atherosclerotic plaques and circulating leokocytes. J Lab Clin Med 2000; 136:194-200.

70. Koopman JJ, van Bodegom D, Jukema JW, Westendorp RG. Risk of cardiovascular disease in a traditional African population with a high infectious load: a population-based study. PLoS One 2012;7:e46855.

71. Harmey JH, Dimitriadis E, Kay E, et al. Regulation of macrophage production of vascular endothelial growth factor (VEGF) by hypoxia and transforming growth factor beta-1. Ann Surg Oncol 1998;5:271-8.

72. De Cortie K, Russell NS, Coppes RP, et al. Bone marrow-derived macrophages incorporate into the endothelium and influence vascular and renal function after irradiation. Int J Radiat Biol 2014;90:1-9.

73. Miller SA, Selzman CH, Shames BD, et al. Chlamydia pneumoniae activates nuclear factor kappaB and activator protein 1 in human vascular smooth muscle and induces cellular proliferation. J Surg Res 2000;90:76-81.

74. Molestina RE, Miller RD, Ramirez JA, Summersgill JT. Infection of human endothelial cells with Chlamydia pneumoniae stimulates transendothelial migration of neutrophils and monocytes. Infect Immun 1999;67:1323-30.

75. Kuningas M, May L, Tamm R, et al. Selection for ge- netic variation inducing pro-inflammatory responses under adverse environmental conditions in a Ghanaian population. PLoS One 2009;4:e7795.

76. May L, van den Biggelaar AH, van Bodegom D, et al. Adverse environmental conditions influence age-related innate immune responsiveness. Immun Ageing 2009;30;6-7.

77. Boef AGC, May L, Van Bodegom D, et al. The influence of genetic variation on innate immune activation in an environment with high infectious pressure. Genes Immun 2012;13:103-8.

78. Edington GM. Cardiovascular disease as a cause of death in Gold Coast Africa. Trans R Soc Trop Med Hyg 1954;48:419.

79. Maher D, Waswa L, Baisley K, et al. Distribution of hyperglycaemia and related cardiovascular disease risk factors in low-income countries: a cross-sectional population-based survey in rural Uganda. Int J Epidemiol 2011;40:160-71.

80. Onen CL. Epidemiology of ischaemic heart disease in sub-Saharan Africa. Cardiovasc J Afr 2013;24:34-42.

81. World Health Organization, Department of Measurement and Health Information. Projections of mortality and burden of disease by region, 2006. Available from: http:// www.who.int/healthinfo/statistics/bod_deathbyregion.xls

82. Steyn K, Sliwa K, Hawken S, et al. Risk factors associated with myocardial infarction in Africa: the INTERHEART Africa study. Circulation 2005;6;112: 3554-61.

83. Vorster HH. The emergence of cardiovascular disease during urbanization of Africans. Public Health Nutr 2002;5:239-43. 